\title{
O JORNAL ESCOLAR COMO MÍDIA CONTRA-HEGEMÔNICA - JORNALISMO DE ESCOLA NÃO MODELADO PELO JORNALISMO COMERCIAL DOMINANTE*
}

\author{
Adair Bonini $^{\star *}$ \\ Universidade Federal de Santa Catarina \\ Centro de Comunicação e Expressão \\ Departamento de Língua e Literatura Vernáculas \\ Florianópolis, SC, Brasil
}

\begin{abstract}
Resumo: Neste trabalho é analisada a influência de jornais alternativos no processo de configuração midiática de um jornal escolar. Trata-se de uma experiência de ensino e aprendizagem de Língua Portuguesa desenvolvida em uma escola da rede municipal de ensino da cidade de Florianópolis/SC, Brasil, da qual participaram 25 estudantes, a professora, e dois pesquisadores. Nessa experiência, desenvolvida sob a égide da Análise Crítica de Gêneros (BONINI 2011; 2013), foram utilizados, como base do trabalho pedagógico, jornais alternativos - de bairro, de igreja, de partido, etc. Buscou-se, neste estudo, considerando as fases do processo de produção do jornal escolar, verificar o tipo de mídia construída e se ela se alinharia, em alguma medida, com um perfil de mídia contrahegemônica.
\end{abstract}

Palavras-chave: Jornal escolar. Mídia. Gêneros do discurso. Contra-hegemonia.

1 INTRODUÇÃO

A construção de jornais escolares é uma atividade bastante produtiva no ensino e aprendizagem de Língua Portuguesa, favorecendo que tanto estudantes quanto professores desenvolvam saberes sobre a língua, a interação pela linguagem e a atuação social.

Quando se fala em jornal escolar no ensino de Língua Portuguesa, no contexto brasileiro pós-PCNs (Parâmetros Curriculares Nacionais) (BRASIL, 1998), naturalmente vem-nos associado o conceito de gênero do discurso. Mas outro conceito que também pode ser fundamental para se pensar essas experiências é o de mídia. Se, quando interagimos, o fazemos por meio de um gênero, não é raro que, ao mesmo tempo, esse gênero esteja chegando a interlocutores através de uma mídia, o que é o caso, por exemplo, do jornal escolar.

\footnotetext{
* Pesquisa financiada pelo CNPq (PQ 312033/2012-5). Texto apresentado no V Simpósio Mundial de Estudos de Língua Portuguesa, realizado em Lecce, Itália, no período de 8 a 11 de outubro de 2015.

** Doutor em Linguística pela Federal de Santa Catarina (UFSC) e professor dessa mesma universidade, atuando no Programa de Pós-Graduação em Linguística e no Programa de Mestrado Profissional em Letras. Email: adair.bonini@gmail.com.
} 
Como mídia, o jornal e o tipo de mediação que ele produz são frutos de uma construção social. No ambiente educacional, o jornal escolar como mídia dos/as estudantes pode ser construído com implicações sociais diversas, dependo do modo como se dá esse processo. Neste artigo discuto o conceito de mídia no cenário de uma experiência de ensino e aprendizagem de Língua Portuguesa via jornal escolar. São analisados dados de pesquisa relativos ao impacto da presença de jornais alternativos no processo de construção de um jornal escolar e, portanto, no tipo de identidade que ele ganhou.

Trata-se de uma experiência de ensino e aprendizagem de Língua Portuguesa desenvolvida em uma escola da rede municipal de ensino da cidade de Florianópolis/SC, Brasil, da qual participaram 25 estudantes, a professora da turma, e dois pesquisadores. Por ser um trabalho que tinha embasamento em teoria crítica, buscamos, desde o início, colocar os/as estudantes em contato com a diversidade de jornais, principalmente considerando que eles/elas pudessem emparelhar projetos alternativos ao jornalismo convencional dominante. Desse modo, entraram em cena jornais de bairro, de igreja, de partido, de sindicato, que, de algum modo, deslocam o papel, que seria até certo ponto previsível, do jornalismo comercial hegemônico como fio organizador das atividades.

A Análise Crítica de Gêneros (doravante ACG) (BONINI 2011; BONINI, 2013) foi um embasamento teórico que teve impacto na organização da prática educativa desenvolvida, embora não tenha sido o único quadro teórico mobilizado. A análise dos resultados da experiência aqui também encampa esse embasamento teórico, ao verificar o modo como a interação via gênero pode ganhar contornos de engajamento social, nesse caso principalmente ao se verificar a construção do jornal escolar para além do horizonte da prática jornalística hegemônica.

A análise de como a experiência transcorreu pode contribuir para construções de outras experiências similares que dela possam se beneficiar a partir deste relato. Ao focalizar a construção da mídia, procuro evidenciar a sua possível conjunção com práticas jornalísticas transformadoras, aqui denominadas práticas jornalísticas contrahegemônicas.

\section{UMA EXPERIÊNCIA COM O JORNAL ESCOLAR}

O trabalho ocorreu em uma turma do Colégio Almirante Carvalhal, unidade da rede municipal de ensino de Florianópolis/SC. Além de 25 estudantes, como já dito acima, tomaram parte da experiência a professora da turma, uma pesquisadora assistente, aluna da Pós-Graduação em Linguística da UFSC, e eu, sendo que a esses últimos denomino, para fins de exposição nesse artigo, mediadores dessas atividades na turma.

Procuramos, ao mediar a experiência, seguir os moldes de uma pesquisa participante, na qual uma prática seria construída e avaliada por todos (DEMO, 2008). Nem sempre, contudo, conseguimos viabilizar espaços de reflexão sobre as atividades simultaneamente como prática social e pesquisa, o que fez com que a experiência, em muitos momentos, se aproximasse de uma pesquisa-ação (THIOLLENT, 2011). Embora os dados gerados tenham sido de diversas naturezas, considero aqui principalmente dados documentais e de observação. 
As atividades, nessa turma, duraram um ano e dois meses, período no qual foram produzidos dois jornais escolares. Para esse fim, foram utilizadas, para elaborar o primeiro jornal, duas aulas semanais (das quatro de Língua Portuguesa que a turma tinha), ministradas em conjunto pela professora e pelos dois pesquisadores. Para a produção do segundo jornal, foram utilizadas duas aulas a cada 15 dias.

Os encontros podem ser agrupados em três fases: a) a de planejamento do jornal, com cinco encontros, ocorridos em novembro e início de dezembro de 2013 ; b) a de produção do primeiro número do jornal, que ocorreu durante o primeiro semestre de 2014; e c) a de produção do segundo número do jornal, desenvolvida durante o segundo semestre de 2014. Neste artigo, enfocarei atividades das fases a) e b) (mas principalmente da a) que tangem ao tema aqui abordado: a construção do jornal escolar como mídia contra-hegemônica.

A ACG, como abordagem teórica (BONINI, 2013; BONINI 2011; BONINI, 2010), esteve presente na condução das atividades, à medida que se procurou criar um clima de debate democrático e construção coletiva. Desse modo, o jornal foi implementado, desde o início, como um projeto coletivo, onde todos teriam direito a propor alternativas, defender posições e votar. No quadro de uma abordagem crítica, para que o debate se produza, é necessário que haja exploração de pontos de vistas diferentes, o que pode ser proposto por cada um dos participantes. Trata-se de desafiar a visões estabilizadas da realidade, e o modo como elas, muitas vezes, produzem relações sociais desiguais. Nesse contexto é que se pensou em inserir os jornais alternativos, comunitários, contrahegemônicos, em contraposição aos jornais convencionais comerciais hegemônicos.

A ACG volta a ser utilizada, nessa análise, como forma de se refletir sobre o que avançou em termos de produção de debates, engajamento e desestabilização de práticas naturalizadas conservadoras e assimétricas. Para melhor embasar a discussão dos dados que farei mais adiante, passo a uma breve exposição sobre a ACG.

\section{ACG E APRENDIZAGEM CRÍTICA DE LÍNGUA PORTUGUESA}

Os trabalhos desenvolvidos dentro da perspectiva da ACG focalizam o gênero a partir de uma aproximação com o quadro teórico da Análise Crítica do Discurso, principalmente com a proposta Faircloughiana (FAIRCLOUGH, 2003; CHOULIARAKI; FAIRCLOUGH, 1999).

Um dos pontos principais nessa aproximação é o de se entender os gêneros como meios de realização de práticas sociais, sendo estas concebidas, neste caso, como "formas habituais, ligadas a tempos e lugares específicos, por meio das quais as pessoas utilizam recursos (materiais ou simbólicos) para agirem juntas no mundo" (CHOULIARAKI; FAIRCLOUGH, 1999, p. 21, com tradução de RESENDE; RAMALHO, 2004, p. 193). ${ }^{1}$ Essas maneiras habituais de agir em conjunto são constituídas tanto de discurso/semiose, quanto de atividade material, participantes, fenômeno mental e relações sociais (CHOULIARAKI; FAIRCLOUGH, 1999). Conforme Figueiredo e Bonini (no prelo):

\footnotetext{
${ }^{1}$ Conceito inspirado nas reflexões de Harvey (1990). 
As práticas sociais se tornaram o foco atual das perspectivas discursivas críticas (ACD, ACG) por serem dimensões intermediárias entre as estruturas sociais (e seus mecanismos) e os eventos sociais concretos e específicos - um extrato intermediário entre a 'sociedade' e as pessoas vivendo suas vidas diárias.

Outro ponto de aproximação é o fato de a ACG, como a ACD (FAIRCLOUGH, 2003), estudar o texto e a interação "como parte de discussões em torno de um problema social" (BONINI, 2010, p. 490), participando de debates relativos à construção simbólica do mundo em questões como violência de gênero, desigualdades de classe, imperialismo, dominação cultural e midiática, etc. Consiste, portanto, em uma perspectiva "orientada para acessar como o momento discursivo funciona dentro da prática social, do ponto de vista de seus efeitos sobre lutas pelo poder e relações de dominação" (CHOULIARAKI; FAIRCLOUGH, 1999, p. 67).

Trabalha-se, assim, com a perspectiva de que sujeitos (homens/mulheres) sociais podem construir agências emancipadoras, desenvolvendo representações críticas sobre o mundo e as relações sociais. Essa agência é constituída no interior de um movimento dual da estrutura (cf. GIDDENS, 1984). Ou seja, a estrutura social (conjuntos de regras e recursos implicados, de modo recursivo, na vida social) "é tanto condição, ou causa material, para a ação humana, quanto é resultado da atividade humana que, por sua vez, produz e reproduz as estruturas sociais" (FIGUEIREDO; BONINI, no prelo).

Nesses termos, a pesquisa crítica implica a reflexão tanto sobre as ações e interações sociais quanto sobre as estruturas, "no sentido de investigar e gerar entendimentos sobre como os recursos estruturais, condições para as ações sociais, são apropriados e aplicados, de formas conservadoras ou transformadoras, no nível local das práticas sociais" (FIGUEIREDO; BONINI, no prelo).

Em Bonini (2013), proponho que a pesquisa em ACG seja desenvolvida a partir da articulação de três quadros teóricos: a prática social (FAICLOUGH, 2003), entendida como formas habituais de agir no mundo; o gênero, como a forma relativamente estável do enunciado (BAKHTIN, 1953); e a transitividade crítica, como a relação entre vozes, na construção da consciência social (FREIRE, 1967) (Figura 1, mais adiante). ${ }^{2}$ Prática e gênero, por sua vez, como formas no interior das quais há o desenvolvimento da transitividade das consciências, ocorrem no quadro social de ideologias e de lutas por hegemonia social.

De acordo com esse enquadre teórico, o gênero como ação interacional de sujeitos (homens/mulheres) sociais é visto sempre como parte constituinte de práticas sociais, que podem ser de dominação ou emancipação, e que tomam lugar na sociedade por meio de processos dialógicos. É no interior da cadeia discursiva que esses agentes sociais irão construir e implementar projetos de mundo e de existência. A transitividade da consciência, portanto, é parte constituinte desse processo, sendo que a consciência será tanto mais transitiva quanto mais envolver conhecimentos históricos dos eventos sociais, debate e negociação das ações sociais e discursivas.

\footnotetext{
${ }^{2}$ Essa figura não aparece no artigo supracitado. Foi elaborada especialmente para a presente exposição. 
Figura 1 - Planos de estudo na Análise Crítica de Gêneros

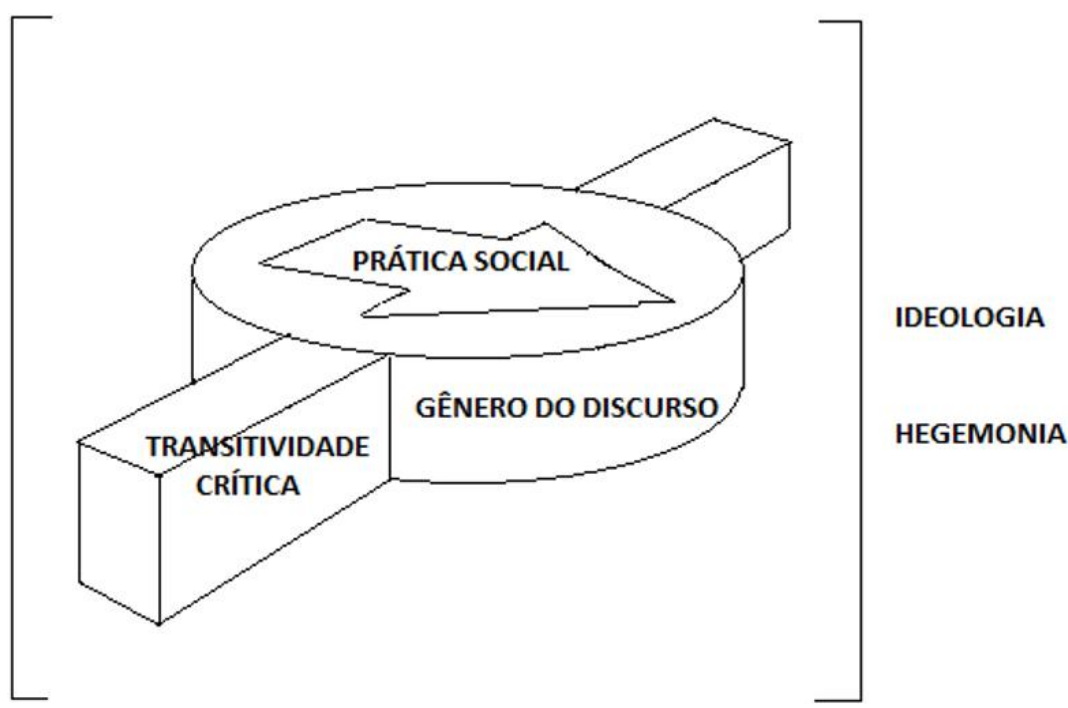

Fonte: Imagem produzida pelo próprio autor.

No campo da educação em linguagem, uma ACG, como a aqui proposta, que considera esses três aspectos (prática social, gênero e transitividade) implica tanto uma metodologia de atuação de sujeitos (homens/mulheres) em situação de aprendizagem rumo a uma atuação crítica e politizada quanto uma forma de observar os eventos e a linguagem em sua ocorrência. Ou seja, parte-se do princípio de que é possível desenvolver atuação e aprendizagem críticas mediante projetos de trabalho com práticas e gêneros do discurso e, por sua vez, que esse percurso é analisável com vias a reconstruções de representações e avanços sociais.

\section{MÍDIA CONTRA-HEGEMÔNICA}

Para a discussão aqui empreendida, volto a uma conceituação que propus anteriormente (BONINI, 2011, p. 693), na qual a mídia é definida como "tecnologia de mediação da interação linguageira e, portanto, do gênero como unidade dessa interação". Isso significa que os gêneros do discurso circulam em mídias que lhes impõem condições de circulação, produção e interpretação. Desse modo, se o gênero e a interação ocorrem via rádio, tevê ou jornal, há todo um conjunto de especificidades que se interpõem entre um polo e outro da enunciação. Ou seja, se no rádio a interação ocorre com base apenas na interação oral sem contato visual, a mediação favorece a ocorrência de determinados elementos de linguagem (como a entonação) e impede outros (como o gesto).

Em consideração a essas especificidades da mediação, defendi (BONINI, 2011, p. 688) que "cada mídia, como tecnologia de mediação, pode ser identificada pelo modo como caracteristicamente é organizada, produzida e recebida e pelos suportes que a constituem". Para além de especificidades de suporte, pode-se entender assim que as mídias são construídas socialmente. Ou seja, um canal de tevê como um dispositivo mediador não funciona apenas com som e imagem em movimento, mas será um canal de notícias (Record News, CNN Internacional, CNN Latina, etc.), de divulgação científica (National Geographic, Explorer, etc.), e assim por diante. Pode-se dizer que uma mídia é um dispositivo mediador, porque essa mediação é construída socialmente, não se restringindo aos suportes físicos nela empregados. 
Como mediação constituída socialmente (por meio de decisões sobre forma de organização, objetivos, interlocutores, forma de circulação, enunciadores, etc.), os jornais são diferentes entre si. Assim, se um jornal é produzido como voz de uma comunidade, de uma secretaria de cultura, de uma empresa de comunicação, de uma empresa aérea, ele perfaz mídias distintas que incorporam também discursos constitutivos distintos.

Do modo como a esfera jornalística está hoje socialmente organizada, há um tipo de jornalismo e de jornal que aparece como dispositivo padrão, convencional, e que encampa marcas como a simulação tanto de um efeito de neutralidade quanto de representação de uma voz coletiva (na medida em que reivindica para si a credencial de ser a tribuna da democracia e, em alguma medida, de se posicionar como sendo o dispositivo que assegura a existência da democracia). Esse jornalismo (empreendido no interior de grandes empresas de mídia como a Folha de S. Paulo, Grupo Globo, O Estado de S. Paulo, RBS) é dominante tanto em poder econômico e político quanto em termos da dispersão social e geográfica de suas práticas.

Em oposição aos jornais convencionais, pode-se falar em diversas outras mídias que as eles se opõem. O jornal comunitário, por exemplo, é uma mídia que se posiciona como voz de um grupo específico (seja um bairro, um movimento, uma tribo urbana), o que difere dessa voz geral que o jornal comercial convencional pretende representar. A figura 2 mostra uma capa do jornal comunitário Folha de Coqueiros na qual podemos observar (seja na foto seja na manchete e no uso do verbo "querem") essa ligação entre a mídia, a voz e as práticas comunitárias que ela representa.

Figura 2 - Jornal comunitário do Bairro de Coqueiros (ano 18, n. 168, de outubro de 2013), em Florianópolis/SC

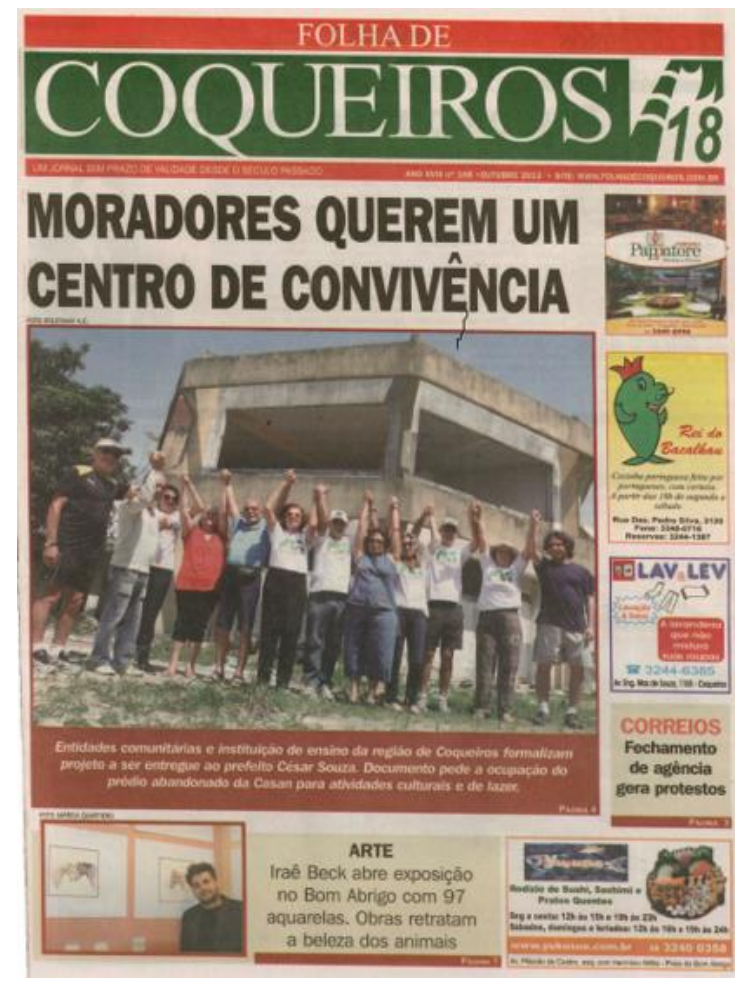

Fonte: Texto coletado em campo e escaneado.

BONINI, Adair. 0 jornal escolar como mídia contra-hegemônica - jornalismo de escola não modelado pelo jornalismo comercial dominante. Linguagem em (Dis)curso - LemD, Tubarão, SC, v. 17, n. 2, p. 165-182, maio/ago. 2017. 
Os jornais comunitários são mídias alternativas ao jornal convencional e, como tal, em alguma medida questionam o papel dominante desse último. Ou seja, são projetos contra-hegemônicos em diversos graus de oposição, a depender dos grupos e práticas aos quais estejam ligados. Na figura 3, por exemplo, temos dois jornais que se posicionam em lugares diversos em um polo contra-hegemônico. Se ambos põem em cena perspectivas e projetos não dominantes, o fazem também de lugares diferentes em termos da teia de relações a que estão filiados. Como oposição à imprensa burguesa dominante, o Opinião Socialista, contudo, traz manchetes e ilustrações mais alternativas, em tudo se opondo ao foco que é dado nos "grandes" jornais. Interessa-me, aqui, pensar possibilidades de o jornal escolar não reproduzir o convencional, constituindo-se como mídia comunitária, mas também, e principalmente, contra-hegemônica, motivo pelo qual passo a uma maior especificação desse tópico.

Figura 3 - Jornais contra-hegemônicos em graus distintos (Opinião Socialista, ano 16, n. 468, de 18 de setembro a $1^{\circ}$ de outubro de 2013; O Jornal Batista, ano 113, n. 41, de 13 de outubro de 2013)
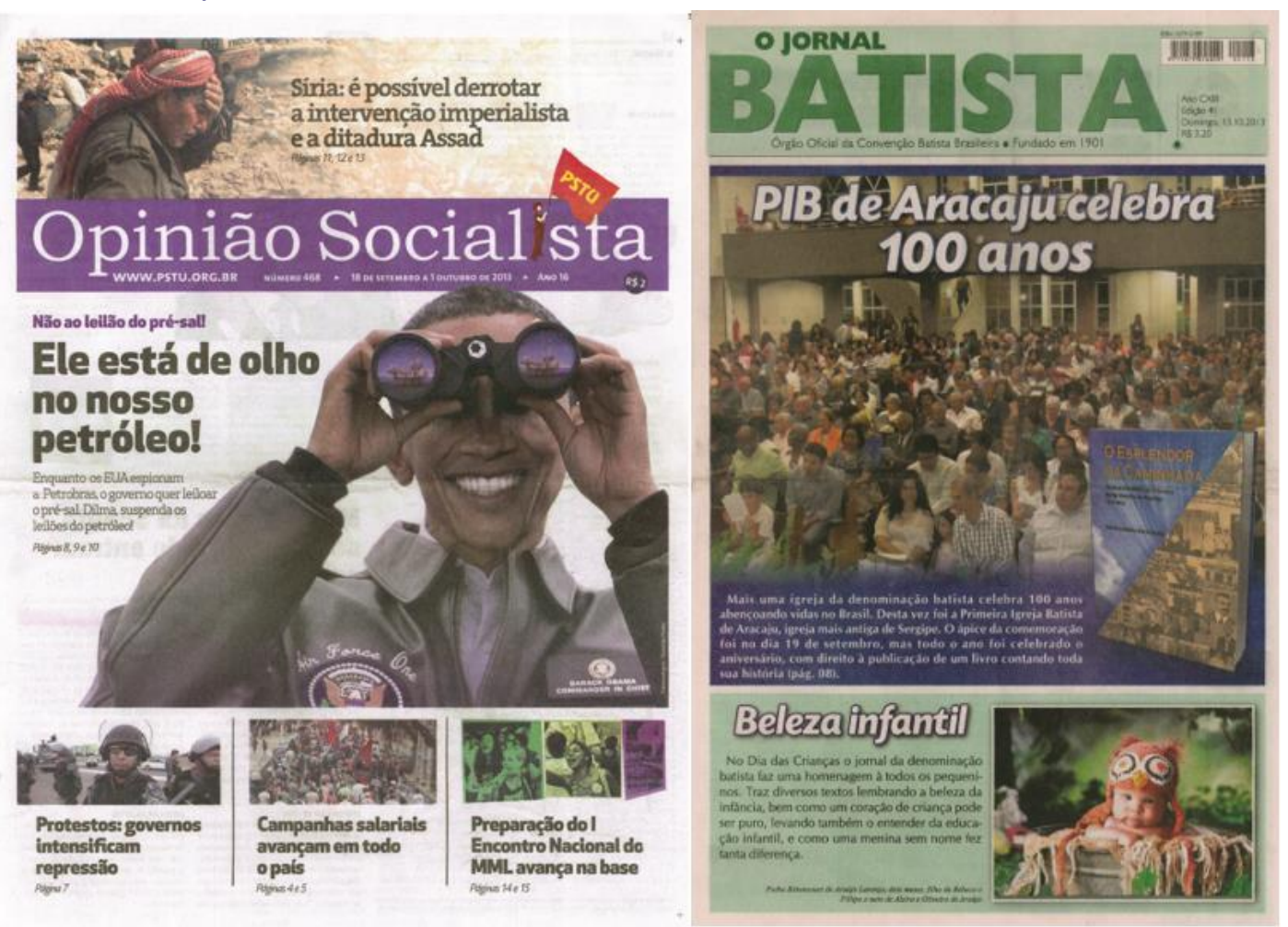

Fonte: Textos coletados em campo e escaneados.

Gramsci (2014 [193?]), diluidamente em sua obra (mas vou me ater aqui ao volume dois de Cadernos do cárcere), explica hegemonia como um mecanismo ideológico de estabelecimento e manutenção do poder dominante, à medida que ela é resultado de um processo de imposição "suave", pelo convencimento, da visão de mundo de uma classe sobre outras. Conforme aponta Costa $(2011$, p. 5), "a hegemonia seria a capacidade de um grupo social unificar em torno de seu projeto político um bloco mais amplo não homogêneo, marcado por contradições de classe". Aos grupos não alinhados, para que 
não desconfigurem a ordem estabelecida, faz-se uso do argumento da força. A hegemonia é constituída essencialmente pela ação de intelectuais, à medida que cabe a eles/elas, como "prepostos/as" do grupo dominante, a produção do consenso "espontâneo" junto aos grupos alinháveis (função atribuída a professores, jornalistas, escritores, políticos, cientistas, religiosos) e a coerção pelo aparelho estatal aos grupos que não consentem (função atribuída a militares, juristas, administradores públicos), essa última ação também disposta para os momentos de crise em que o consenso "espontâneo" se rompe.

Gramsci fala em dois tipos de intelectuais. O primeiro grupo compreende intelectuais tradicionais, que correspondem a categorias de intelectuais preexistentes, provenientes "da estrutura econômica anterior [...], representantes de uma continuidade histórica”. Ligado à aristocracia, o eclesiástico seria um desses exemplos de grupo intelectual tradicional. $\mathrm{O}$ outro é o grupo composto por intelectuais orgânicos/as, que surgem como peça chave da organização e sustentação do poder de determinado grupo dominante. Nesses termos é que o autor afirma que "o empresário capitalista cria consigo o técnico da indústria, o cientista da economia política, o organizador de uma nova cultura, de um novo direito etc. etc." (GRAMSCI, 2014 [193?], p. 15).

Nessa perspectiva do/a intelectual orgânico/a, todos/as que compõem o grupo são intelectuais, embora nem todos/as possam estar em funções intelectuais. A condição de transformação social implica a construção e implementação de projetos contrahegemônicos, ou seja, o/a intelectual orgânico/a transformador/a não se concentra na eloquência e na oratória, mas na gestão contínua e prática da vontade coletiva, visando à instauração de uma nova hegemonia menos injusta. Por isso é que Gramsci (2014 [193?], p. 54) afirma que o novo intelectual, "da técnica-trabalho, chega à técnica-ciência e à concepção humanista histórica, sem a qual permanece 'especialista' e não se torna 'dirigente' (especialista + político)".

A proposição e a sustentação de projetos contra-hegemônicos exigem a materialização de novas ideologias, uma vez que elas "são as formas pelas quais os sujeitos históricos adquirem consciência da sua posição de classe e do conflito em que estão situados, assumindo a luta e a conduzindo até o fim" (COSTA, 2011, p. 9).

Gramsci (2014 [193?]) fala de uma nova hegemonia vinda das classes populares para suplantar a hegemonia liberal burguesa. Como continuador do pensamento gramsciano, agora já posicionado no período do novo capitalismo (global, neoliberal), Santos (2009) propõe a ideia de uma globalização contra-hegemônica com a defesa de uma epistemologia pós-abissal, na qual as vozes do Sul Global pudessem ser mobilizadas na reorganização de um mundo que contemplasse uma ecologia de saberes. Nessa proposta, a emancipação se daria em um plano para além das hierarquias das classes sociais, uma vez que os saberes e culturas não ocidentais (de indígenas, por exemplo) também estariam contando para a composição de um mundo menos opressivo. A globalização contra-hegemônica "consiste num vasto conjunto de redes, iniciativas, organizações e movimentos que lutam contra a exclusão económica, social, política e cultural gerada pela mais recente encarnação do capitalismo global, conhecido como globalização neoliberal" (SANTOS, 2009, p. 42).

Conforme Mclaren e Farahmandpur (2012, p. 29), o capitalismo pós-Segunda Guerra desenvolveu-se com base na "centralização do poder social, político e econômico 
nas mãos de um número relativamente pequeno de oligopólios" e na "transferência de capital competitivo dos países ocidentais para os mercados mais baratos e, portanto, dando crescimento ao cultuado fenômeno conhecido como 'globalização do capital'". E a globalização, nos planos econômico (infraestrutural) e cultural (superestrutural) gera toda uma organização de mundo que camufla a exploração. Seja via mídia, seja pela ação de inúmeros dispositivos sociais (como as universidades), tem-se a impressão de que a opressão desapareceu e de que a pobreza, a fome e a violência são decorrentes das irresponsabilidades dos próprios sujeitos (homens e mulheres). Somos levados/as a conclusões quase invertidas sobre a realidade social, ao que McLaren e Farahmandpur (2012, p. 36) acrescentam: "a tese da globalização sustenta que enquanto o poder do Estado pode ser usado nos interesses das grandes corporações multinacionais, este poder não pode ser usado nos interesses da classe trabalhadora".

Os jornais contra-hegemônicos, no Sul Global, abrem espaço para outras práticas e explicações da realidade. A lógica comercial da informação e o próprio termo informação estariam sobre escrutínio. Neles, soma-se a ampliação da quantidade de vozes em circulação a um desvelamento dos mecanismos ordenadores e limitadores da realidade até então presididos pela lógica do capitalismo tardio e pela hegemonia ocidental (ocidental no sentido de SAID, 1978). Não se trata, portanto, da inclusão de grupos excluídos no mesmo mundo do Norte Global (com todas as restrições que esse termo implica), mas da revisão dos parâmetros de organização do mundo, onde a diversidade seja, de fato, um dado potencializador da mudança.

O jornal escolar modelado pela mídia jornalística hegemônica trabalha em função da opressão, da manutenção e do fortalecimento do mesmo contorno de mundo, com a tísica democracia de vozes e parcas possibilidades de mudanças que essa mídia implica. Mas se o jornal é escolar não modelado pela mídia dominante, ele pode representar os sujeitos (homens/mulheres) e a ação construtora local. Nesse sentido, ele pode ser um jornal comunitário. E sua ação política pode ser ainda mais questionadora, ao viabilizar o questionamento dos lugares sociais e ao dar ensejo a uma ecologia de saberes contrahegemônica.

Um jornal escolar contra-hegemônico oportuniza a revisão das práticas jornalísticas hegemônicas (do falso efeito de imparcialidade, por exemplo, que se mantêm nos discursos e na estruturação das mídias jornalísticas dominantes). Mais que isso, ele favorece a emersão de identidades, práticas e representações questionadoras do Norte Global (dominado secularmente pelo gênero masculino heteronormativo, pela etnia branca, e pelas classes economicamente mais poderosas).

O mesmo que defende Giroux (1988) sobre o lugar do/a professor/a como intelectual transformador/a é possível defender para os/as estudantes. Para isso, é necessário tornar o pedagógico mais político, inserindo "a escolarizacão diretamente na esfera política, argumentando-se que as escolas representam tanto um esforço para definir-se o significado quanto uma luta em torno das relações de poder" (p. 163). No mesmo sentido, também é importante tornar a política mais pedagógica, utilizando

\footnotetext{
formas de pedagogia que incorporem interesses políticos que tenham natureza emancipadora; isto é, utilizar formas de pedagogia que tratem os estudantes como agentes críticos; tornar o conhecimento problemático; utilizar o diálogo crítico e afirmativo; e argumentar em prol de um mundo qualitativamente melhor para todas as pessoas. (p. 163).
} 
No jornal escolar contra-hegemônico, o/a estudante é chamado/a a ocupar um papel de intelectual orgânico/a transformador/a. O jornal escolar contra-hegemônico emerge em si como resultante de seu próprio debate fundacional, que incorpora desde o início uma prática transitiva crítica (FREIRE, 1967), voltada para o questionamento e o trânsito entre visões de mundo.

\section{JORNAL ESCOLAR COMO MÍDIA CONTRA-HEGEMÔNICA}

O trabalho em sala de aula se inspirou na metodologia da pesquisa participante (DEMO, 2008). De modo geral, as decisões durante o projeto foram sempre tomadas a partir de reuniões com todos e todas que dele fizeram parte. A ideia de se produzir um jornal, contudo, não nasceu espontaneamente dos/as estudantes, mas foi uma proposta do pesquisador e da pesquisadora trazida para o grupo.

A análise desenvolvida neste artigo toma como foco os eventos que ocorreram relacionados à construção do jornal escolar em questão que, de alguma forma, ensejam práticas contra-hegemônicas. Para efeitos dessa reflexão, são considerados os vários momentos do processo de produção do jornal escolar, mas principalmente os eventos ocorrentes durante o planejamento da mídia.

O início do trabalho com o jornal, como já dito acima, foi o segundo semestre de 2013. Tínhamos possibilidade de cinco encontros de trabalho com a turma, antes que o ano acabasse. Propusemos que esse tempo fosse voltado ao planejamento do jornal que iríamos produzir no ano seguinte. Apresentamos a ideia do projeto à turma e, havendo acordo, propusemos um roteiro de atividades: que se iniciavam com a leitura de jornais, reconhecimento da organização dos jornais, de quem interage neles e do lugar onde circulam, indo até o esboço de como seria o jornal da turma (com título, primeira página e seções).

Nesse período, quatro eventos chamam a atenção: o uso de jornais alternativos, a palestra de jornalistas comunitários, a discussão do nome do jornal, e a definição das seções.

\subsection{JORNAIS ALTERNATIVOS}

O uso de jornais alternativos foi um dos aspectos que mais marcaram essa experiência de ensino e aprendizagem via jornal escolar. Tomamos como base das atividades, nesse primeiro momento, o jornal do bairro onde a escola se situa: o jornal Folha de Coqueiros. Esse jornal favorecia o trabalho, pois, além de ser uma mídia de convívio rotineiro dos/as estudantes, também tinha distribuição gratuita, o que possibilitava que cada estudante tivesse o seu exemplar para leitura e análise.

A partir dessa decisão, coletamos diversos outros jornais alternativos para que os/as estudantes tivessem à disposição uma amostra suficientemente variada. Além da Folha de Coqueiros, eles/as tiveram contato com: Ô Catarina (jornal da Fundação Catarinense de Cultura), Opinião Socialista (do PSTU), Jornal Regional (jornal comercial gratuito), 
O Bom Samaritano (da Igreja Assembleia de Deus), O Jornal Batista (da Igreja Batista), Jornal Universitário (da UFSC), Zero (jornal laboratório do Curso de Jornalismo da UFSC). Esses jornais alternativos eram trabalhados em comparação com os jornais comerciais convencionais: Diário Catarinense (do Grupo RBS) e Notícias do Dia (do Grupo Record).

Foram propostas diversas atividades como a de comparar jornais, debater textos publicados, identificar itens da primeira página. Em geral, tais atividades favoreceram que os/as estudantes formulassem uma explicação para a organização do jornal. Essa fase, contudo, poderia ter sido explorada em maior profundidade, com maior tempo, aspecto que pode ser considerado em futuras experiências que tomem jornais alternativos e jornais contra-hegemônicos como base de trabalho, em contraste com jornais dominantes convencionais. Um tempo maior de trabalho, aliado a ações de pesquisa e debate, podem render uma reflexão mais empoderadora quanto às possibilidades de ação dos/as estudantes no jornal escolar e também uma representação mais nítida das diferenças entre jornalismo contra-hegemônico e hegemônico e entre jornalismo alternativo e convencional. Além disso, nós mediadores poderíamos ter sugerido atividades que demandassem um nível maior de comparação entre jornais hegemônicos e contrahegemônicos.

Uma experiência como essa favorece a reflexão sobre a importância de os/as estudantes poderem tanto reconhecer e debater os discursos que circulam nessa variedade de jornais quanto perceber o modo como os gêneros de discurso estruturam práticas noticiosas diversas. Parece ser fundamental, além disso, que eles/as possam estabelecer a relação entre os jornais e as lutas que estão sendo travadas na construção das instituições e, de modo mais amplo, das estruturas sociais.

\subsection{JORNALISTAS COMUNITÁRIOS/AS}

Um segundo evento importante dessa fase foi a presença, na escola, de jornalistas de periódicos comunitários, o que ocorreu no segundo encontro do trabalho com o jornal escolar. Foram conversar com os/as estudantes a jornalista Sybila Loureiro, editora da Folha de Coqueiros, e o jornalista Dagoberto Bordin, ex-editor do antigo jornal Espinheira (jornal comunitário da praia da Pinheira), atuando, na época, como diretor da Radio Comunitária Pinheira. Ambos falaram do trabalho do jornalista e de como se envolveram com o jornalismo. Sybila tratou complementarmente de aspectos bem específicos da edição de um jornal comunitário, como as escolhas de pautas e a manutenção financeira do jornal através da venda de anúncios.

Houve grande interesse por parte dos/as estudantes. Praticamente toda a sala fez perguntas, que versavam sobre os seguintes temas:

a) a formação do/a jornalista - A faculdade de jornalismo é muito difícil? Precisa estudar muito tempo? Como é ser jornalista? Precisa de muito estudo? O que incentivou a senhora a ser jornalista?

b) o trabalho do/a jornalista - Como é ser repórter? Qual é a parte mais difícil para um jornalista? Há quantos anos vocês estão no jornalismo? Qual é a maior 
dificuldade que você teve no jornal? Você precisa ir para muitos lugares? Você já ficou muitos dias sem dormir? Como vocês ficam sabendo das notícias?

c) o jornal - Quem faz o jornal? O que é mais difícil? Qual é a parte mais importante do jornal? Quem faz a revisão do jornal? Por que os jornais de televisão são mais vistos?

d) o jornal escolar - Nós poderíamos fazer um bom jornal?

Muitas das perguntas abordavam a formação profissional do/a jornalista, sobre como começar na profissão, etc. O tema do jornal comunitário, contudo, foi pouco explorado nas questões e o jornal escolar recebeu apenas uma questão. Essa configuração das questões pode estar relacionada a três fatores: a) pelo fato de o trabalho com o jornal estar apenas no segundo encontro, tendo os/as estudantes ainda pouca discussão acumulada sobre os jornais alternativos; b) em virtude de as falas dos/as jornalistas terem possivelmente mobilizado mais esse assunto do que o funcionamento dos jornais comunitários - uma orientação de fala que poderia ter sido feita pelas mediadoras e pelo mediador; e c) em função da massiva circulação das representações glamourizadas da identidade e do trabalho do/a jornalista.

As falas da jornalista e do jornalista, contudo, parecem ter sido um dos pontos altos da experiência em termos de reflexão e motivação, com grande avanço em termos de aprendizagem e envolvimento por parte dos/as estudantes e de mediadores. É certamente um tipo de atividade essencial, a que se pode recorrer para o desenvolvimento de práticas críticas em futuras experiências com o jornal escolar.

\subsection{O NOME DO JORNAL ESCOLAR}

Um terceiro evento importante, ainda nessa primeira etapa do trabalho com a turma, foi a discussão sobre o nome do jornal. Após discussão em grupos, todos os nomes propostos foram listados no quadro, gerando uma lista sequencial de 11 nomes. Observando agora em retrospecto essa lista, pode-se notar que os nomes propostos tematizavam centralmente três aspectos:

a) o nome da escola - Almirante; Carva; De Olho no Carva; Educarvalhal; Folha do Carva; Ilha do Carvalhal; Olho do Carva; O Mirante Carvalhal;

b) a escola em si - De Olho na Escola; Aquarela;

c) a faixa etária dos/as estudantes - Descolado; Jornal Teen.

Houve defesa de nomes e votação nominal, sendo que "De Olho no Carva" recebeu o maior número de votos. A concepção de olho incluía um desenho de olho que entraria como parte do nome. Esse aspecto gráfico parecer ter sido o mais relevante na escolha dos/as estudantes. Da parte do mediador e das mediadoras, entendemos que a metáfora do "olho" remetia a certo discurso de imprensa justiceira - aquela que toma para si o papel de apontar o que entende como sendo "problemas sociais" e fazer cobranças, não raro tendendo a discursos puristas e autoritários. Defendemos, de acordo com nossa posição, o nome "O Mirante Carvalhal". 
Como base na premissa de que essa questão do nome do jornal poderia render maiores discussões sobre a linha editorial do jornal e sobre questões envolvendo o papel da mídia jornalística na sociedade, retomamos as defesas de nomes e a votação (dessa vez, secreta, em cédulas) quando o projeto reiniciou em 2014 (nos dois primeiros encontros de trabalho). Os nomes defendidos, argumentos apontados e número de votos recebidos foram os seguintes:

a) De olho na escola - olho com um aspecto gráfico; olho significando observar [5];

b) De olho no Carva - mesmo argumento, mas centrando-se nessa escola específica [12];

c) Jornal teen - por causa da idade, por causa do logo da escola que pode ser usado no nome do jornal [4];

d) Mirante do Carva - é a mesma ideia, mas é uma figura mais bonita, poética, do mirante de onde se vê tudo; mirante amplia em relação a olho - essa foi à defesa das mediadoras e do mediador dessa experiência [5].

Um aspecto muito relevante desse momento da experiência foi a possibilidade de os/as estudantes participarem ativamente das decisões, passando por debates de decisões colegiadas. Em geral, os nomes e a linha editorial tenderam a conceber o jornal escolar como mídia da escola, talvez pela influência da própria mediação que fizemos, que apontava para um jornal da turma e da escola. A única proposta que apresentava uma relação mais próxima com a realidade pessoal da turma e da faixa etária foi o Jornal Teen, embora o grupo proponente não tivesse desenvolvido uma proposta consistente. Futuras experiências com o jornal escolar talvez pudessem contemplar um tempo maior de debate e proposição de propostas alternativas, ainda que essa proposta de agregar assuntos da escola e do bairro tenha rendido bons resultados em termos de identidade com a turma e de coerência da publicação. É importante, nesse caso, que eles/as cheguem a um projeto com o máximo de elaborações próprias, a partir das quais os/as mediadores/as possam fazer propostas alternativas sempre que se esteja correndo o risco da reprodução pura e simples da mídia dominante ou para ganho de coerência como projeto. Para a ampliação dos debates e da possibilidade maior criticismo, é importante evitar apenas contemplar o gosto dos/as estudantes, pois isso pode gerar uma prática pedagógica espontaneísta.

\subsection{AS SEÇÕES DO JORNAL ESCOLAR}

Juntamente com a discussão do nome, foram propostos também discussões sobre as seções e matérias que o jornal poderia publicar. Na figura 4, podemos verificar dois desses exercícios (realizados em equipes).

No primeiro esboço (figura 4, acima), temos um jornal já bem organizado, com seções e possíveis matérias de cada uma delas. É interessante notar, além disso, a seção Gastronomia, que se inspira no jornal Folha de Coqueiros, utilizado como material de leitura e análise durante as aulas. No segundo (figura 4, abaixo), podemos notar a questão do olho apontada acima e as várias possibilidades que essa equipe viu para o nome do jornal a partir dessa metáfora. Gastronomia também aparece como seção. 
Outras propostas de nomes do jornal e seções/matérias foram:

a) Almirante - Notícias de trilha; Prova Brasil; Tirinhas; Prova Floripa; Direcionar o jornal para os pais; Moda; Esportes;

b) Carva - Moda; Esporte; Cozinha; Passeios; Diversão; Fofocas;

c) Educarvalhal - Passeios; Avisos; Gincana escolar; Eventos da escola;

d) Jornal Aquarela - Gincana; Festa junina; Brincadeiras na hora do intervalo; Pessoas da escola; Professores divertidos; Teatro e banda da guarda municipal;

e) Jornal Descola Do/ Jornal teen - Moda do momento; Prova do mês; Problemas da escola.

Figura 4 - Esboços de planejamento do jornal escolar na turma 71/81

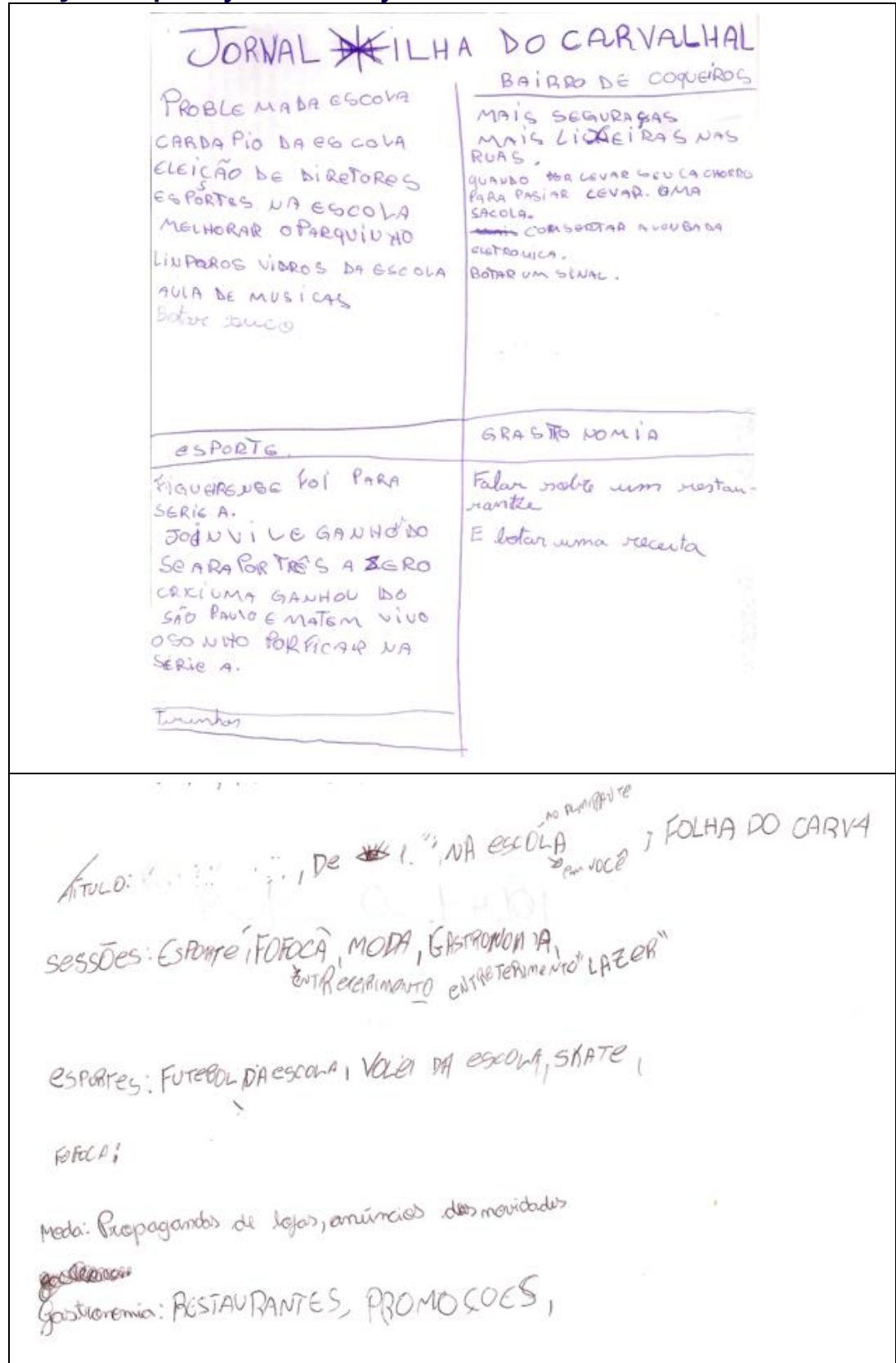

Fonte: Textos coletados em campo e escaneados. 
De modo geral, nem todos os nomes correspondiam a seções. Muitos esboços traziam matérias e seções misturadas ou itens que não eram nem um nem outro (por exemplo, "Direcionar o jornal para os pais").

Considerando a recorrência de certos temas, as mediadoras e o mediador propuseram uma organização em quatro seções: escola, bairro, esportes e entretenimento. O grupo de estudantes aceitou e incorporou uma quinta (moda). Formaram-se, portanto, cinco editorias (cinco equipes) responsáveis cada uma por uma seção. Na fase final, a seção de moda foi incorporada à de entretenimento, embora mantendo duas equipes editoriais.

Nesse primeiro momento, os/as estudantes estavam criando a mídia na qual seus textos circulariam, estavam formulando um projeto autoral que também se projetava a partir das práticas sociais que realizariam.

\section{CONSIDERAÇÕES FINAIS}

Em relação a esse primeiro momento de construção da mídia e dos gêneros a circular no jornal, cabe enfatizar inicialmente o evidente envolvimento dos/as estudantes como sujeitos (homens/mulheres) daquela prática social (de noticiabilidade no âmbito do colégio). Esse é o primeiro e mais relevante aspecto a ser observado em uma atividade com jornal escolar, uma vez que a depender das decisões e ações dos/as estudantes é que o jornal irá ganhar concretude e começar seu percurso histórico como prática e como experiência geradora de saberes. Os/as estudantes puderam se colocar na origem do discurso, concebendo um projeto autoral e interativo, passando por momentos de dialogação e transitividade da consciência.

Outro aspecto a se enfatizar foi o caráter não reprodutivista envolvido na experiência, seja na participação de jornais alternativos e contra-hegemônicos, seja no contato com e discursos diversos, seja nas discussões e decisões colegiadas. É difícil apontar o quanto o jornal escolar publicado (figura 5, mais adiante) tenha se firmado como jornal contra-hegemônico não modelado pelo jornal convencional. Houve, contudo, muitos momentos que favoreceram experiências e saberes desse tipo.

Seria interessante, em futuras experiências, que houvesse a ampliação do espaço de debates, garantindo-se um trato mais específico das fronteiras entre tipos de jornais e as correspondentes lutas sociais envolvidas. Essa densidade maior de debates e pesquisas talvez pudesse ensejar percursos autorais mais próximos da realidade dos/as estudantes. Nessa mesma linha, cabe também uma reflexão sobre percursos de atividades onde os/as mediadores/as possam ser menos diretivos.

Um último item a ser considerado, e talvez o mais importante, é a percepção que se pode ter agora, em retrospecto, de que cada jornal escolar tem uma história própria durante a qual estudantes e mediadores vão vendo outras possibilidades de decisão e condução das atividades. As novas oportunidades surgem como retorno das próprias atividades propostas e isso vai ensejando um tipo de conhecimento encarnado na prática, uma práxis, que oportuniza o desenvolvimento de saberes para estudantes e mediadores. Novos caminhos, portanto, dependem dos caminhos propostos e da coragem de repensar o porvir. 
Figura 5 - Capa do jornal produzido

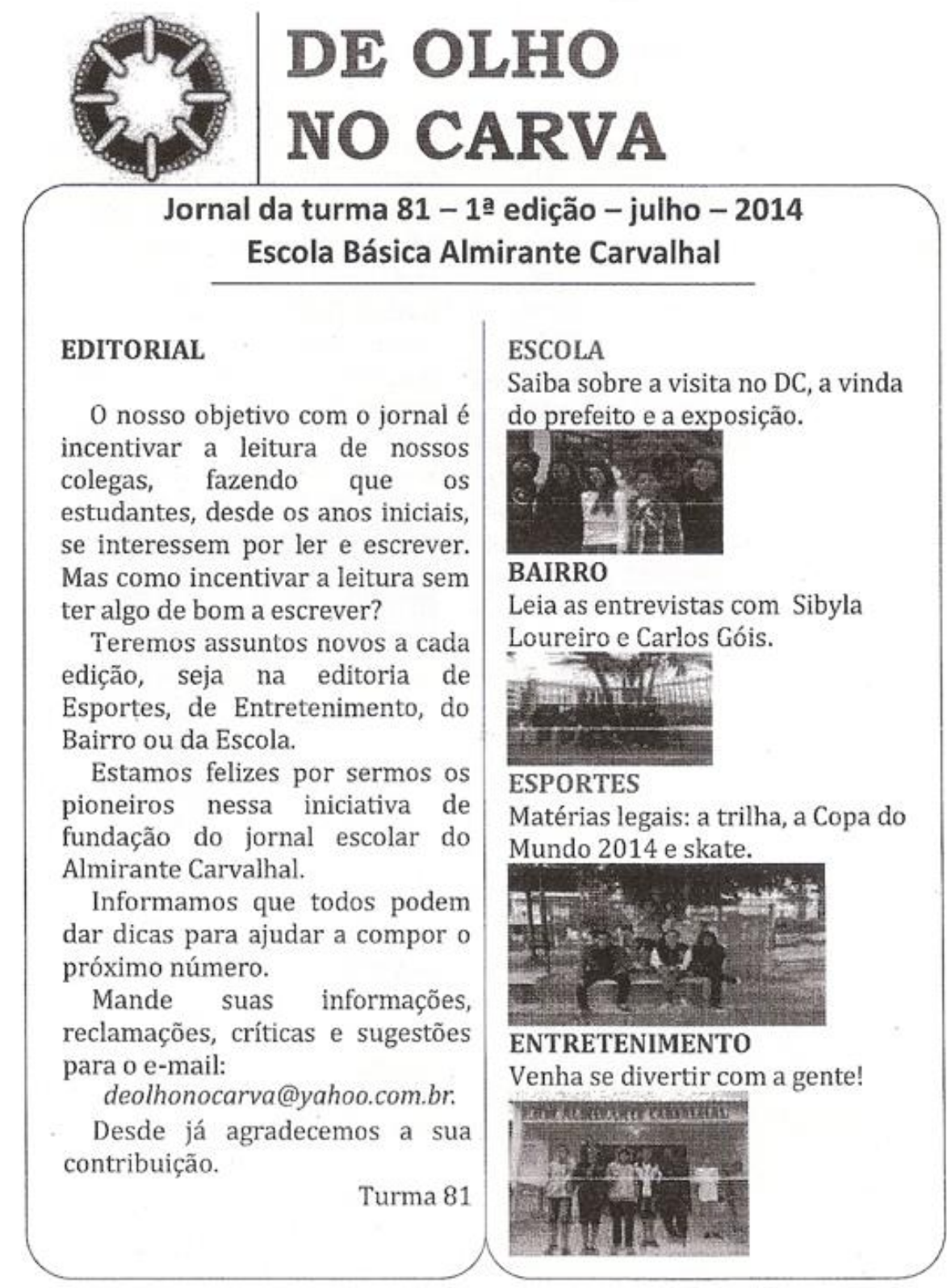

Fonte: Texto coletado em campo e escaneado.

\section{REFERÊNCIAS}

BAKHTIN, M. Os gêneros do discurso. In: BAKHTIN, M. Estética da criação verbal. Trad. de Paulo Bezerra. São Paulo: Martins Fontes, 2006 [1953].

BONINI, A. Critical genre analysis and professional practice: the case of public contests to select professors for Brazilian public universities. Linguagem em (dis)curso, v. 10, n. 3: "Gêneros e atividades profissionais" organizado por Giovanni Parodi e Marcos Baltar, p. 485-510, set./dez. 2010. Mídia / suporte e hipergênero: os gêneros textuais e suas relações. Revista Brasileira de Linguística Aplicada, v. 11, n. 3, p. 679-704, 2011.

Análise crítica de gêneros discursivos no contexto das práticas jornalísticas. In: SEIXAS, L.; PINHEIRO, N. F. (Org.). Gêneros: um diálogo entre Comunicação e Linguística Aplicada. Florianópolis: Insular, 2013. p. 103-120. 
BRASIL. Ministério da Educação. Secretaria de Educação Fundamental. Parâmetros Curriculares Nacionais: terceiro e quarto ciclos do ensino fundamental: Língua Portuguesa. Brasília: MEC/SEF, 1998. CHOULIARAKI, L.; FAIRCLOUGH, N. Discourse in late modernity: rethinking critical discourse analysis. Edinburgh: Edinburgh University Press, 1999.

COSTA, R. da G. R. Gramsci e o conceito de hegemonia. Salvador: Quarteto Editora, 2011. 70 p. Disponível em: <http://institutocaioprado.org.br/icp/?p=70>. Acesso em: 17 mar. 2015.

DEMO, P. Pesquisa participante: saber pensar e intervir juntos. 2. ed. Brasília: Liber Livro, 2008. FAIRCLOUGH, N. Analysing discourse: textual analysis for social research. London: Routledge, 2003. FERRETTI-SOARES, V.; BONINI, A. Gênero e prática social: como a Rede Globo inventa uma identidade positiva a partir do programa “O Sagrado". In: SOUZA, S.; SOBRAL, A. (Org.). Gêneros, entre o texto e o discurso: questões conceituais e metodológicas. Campinas: Mercado de Letras, 2016. p. 173-196.

FIGUEIREDO, D. de C.; BONINI, A. Recontextualização e sedimentação do discurso e da prática social: como a mídia constrói uma representação negativa para o professor e para a escola pública. (no prelo - a ser publicado na revista DELTA).

FREIRE, P. Educação como prática de liberdade. 32. ed. Rio de Janeiro: Paz e Terra, 2009 [1967]. GIDDENS, A. A constituição da sociedade. Trad. de Álvaro Cabral. São Paulo: Martins Fontes, 1989 [1984].

GIROUX, H. A. Os professores como intelectuais: rumo a uma pedagogia crítica da aprendizagem. Trad. de Daniel Bueno. Porto Alegre: Artes Médicas, 1997 [1988].

GRAMSCI, A. Cadernos do cárcere: Volume 2: Os intelectuais. O princípio educativo. Jornalismo. Trad. de Carlos Nelson Coutinho e Luiz Sérgio Henriques. Rio de Janeiro, 2014 [193?].

HARVEY, D. A condição pós-moderna: uma pesquisa sobre as origens da mudança cultural. Tradução de Adail Ubirajara Sobral e Maria Stela Gonçalves. São Paulo: Edições Loyola, 1992 [1990].

KLEIMAN, A. B. Modelos de letramento e as práticas de alfabetização na escola. In: KLEIMAN, A. B. (Org.). Os significados do letramento: uma nova perspectiva sobre a prática social da escrita. Campinas: Mercado de Letras, 1995. p. 15-61.

MCLAREN, P.; FARAHMANDPUR, R. Pedagogia revolucionária na globalização. Trad. de Marcia Moraes. Rio de Janeiro: DP\&A, 2012.

RESENDE, V. de M.; RAMALHO, V. C. V. S. Análise de discurso crítica, do modelo tridimensional à articulação entre práticas: implicações teórico-metodológicas. Linguagem em (Dis)curso, Tubarão, v. 5, n.1, p. 185-207, jul./dez. 2004.

SAID, E. W. Orientalismo: o Oriente como invenção do Ocidente. Trad. de Rosaura Eichenberg. São Paulo: Companhia das Letras, 2007 [1978].

SANTOS, B. de S. Para além do pensamento abissal: das linhas globais a uma ecologia de saberes. In: SANTOS, B. de S. (Org.). Epistemologias do sul. Coimbra: Edições Almedina, 2009. p. 23-71.

THIOLLENT, M. J. M. Metodologia de pesquisa-ação. 18. ed. São Paulo: Cortez, 2011.

Recebido em: 30/09/16. Aprovado em: 28/03/17.

Title: School Newspaper as a Counter-Hegemonic Media - A School Journalism not Framed by Dominant Commercial Journalism

Author: Adair Bonini

Abstract: This paper analyzes the influence of alternative newspapers in a media configuration of a school newspaper. The newspaper was produced as an experiment of teaching and learning Portuguese, developed in a municipal school in Florianópolis/SC, Brazil, whose participants were 25 students, the teacher, and two researchers. In this experiment, which was grounded in Critical Genre Analysis (BONINI 2011; 2013), alternative newspapers - e.g. neighborhood, church, party papers - were used as the basis for pedagogical work. Considering the phases of the production process of specific school newspaper, this study aimed to check the type of media produced and whether it would fit, to some extent, within a counter-hegemonic media profile.

Keywords: School newspaper. Media. Genre. Counter-hegemony.

BONINI, Adair. 0 jornal escolar como mídia contra-hegemônica - jornalismo de escola não modelado pelo jornalismo comercial dominante. Linguagem em (Dis)curso - LemD, Tubarão, SC, v. 17, n. 2, p. 165-182, maio/ago. 2017. 
Título: El periódico escolar como media contra-hegemónicos - periodismo de escuela no modelado por el periodismo comercial dominante

Autor: Adair Bonini

Resumen: En este trabajo es analizada la influencia de periódicos alternativos en el proceso de configuración mediática de un periódico escolar. Se trata de una experiencia de enseñanza y aprendizaje de Lengua Portuguesa desarrollada en una escuela de la red municipal de enseñanza de la ciudad de Florianópolis / SC, Brasil, de la cual participaron 25 estudiantes, la profesora, y dos investigadores. En esa experiencia, desarrollada bajo la égida del Análisis Crítico de Géneros (BONINI 2011; 2013), fueron utilizados, como base del trabajo pedagógico, periódicos alternativos - de barrio, de iglesia, de partido, etc. Se buscó, en este estudio, considerando las fases del proceso de producción del periódico escolar, verificar el tipo de media construida y si ella se alinea, en alguna medida, con un perfil de media contra hegemónica.

Palabras-clave: Periódico escolar. Media. Género del discurso. Contra hegemonia.

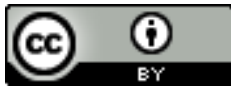

Este texto está licenciado com uma Licença Creative Commons Atribuição 4.0 Internacional. 